\title{
Novel Mutation of the TINF2 Gene in a Patient with Dyskeratosis Congenita
}

\author{
Benjaporn Panichareon ${ }^{a}$ Thanawat Seedapan $^{a}$ \\ Wanna Thongnoppakhun ${ }^{b} \quad$ Chanin Limwongse $^{b, c}$ \\ Manop Pithukpakorn $^{b, c}$ Thawornchai Limjindaporn ${ }^{a}$ \\ ${ }^{a}$ Department of Anatomy, ${ }^{b}$ Division of Molecular Genetics, Department of Research and \\ Development, and 'Division of Medical Genetics, Department of Medicine, Faculty of \\ Medicine, Siriraj Hospital, Mahidol University, Bangkok, Thailand
}

\section{Key Words}

Dyskeratosis congenita $\cdot$ TINF2 $\cdot$ Mutation $\cdot$ Direct sequencing

\begin{abstract}
Dyskeratosis congenita (DKC) is a rare inherited disease that is characterized by abnormal skin pigmentation, nail dystrophy and mucosal leukoplakia. DKC is caused by an abnormality in a component of the telomerase and shelterin complexes. TINF2 encodes a protein in the shelterin complex and TERC encodes a component of the telomerase complex. Mutations of both genes have been associated with DKC. This study examined mutations in TINF2 and TERC by direct DNA sequencing in a Thai patient with DKC. We identified a novel mutation (c.845G $>\mathrm{T}$ ) that is located in exon 6 of TINF2 and changes an arginine to leucine (Arg282Leu). This identified mutation could be applied for molecular genetic diagnosis and genetic counseling of patients with DKC.

(c) 2015 S. Karger AG, Basel
\end{abstract}

\section{Introduction}

Dyskeratosis congenita (DKC) is a rare inherited syndrome caused by a defect in telomere maintenance. The incidence of DKC is approximately $1 / 1,000,000$ individuals [1]. DKC is characterized by the classic clinical triad of abnormal skin pigmentation, nail dystrophy and mucosal leukoplakia [2]. Almost $80 \%$ of DKC patients develop bone marrow failure, which is a major cause of early death. Moreover, DKC is associated with pulmonary fibrosis 
and other malignancies $[3,4]$. DKC is caused by mutations in six genes that encode protein components of the telomerase complex: dyskerin - DKC1, telomerase RNA component $T E R C$, telomerase reverse transcriptase - TERT, NHP2 ribonucleoprotein - NHP2, nucleolar protein 10 - NOP10, and shelterin complex (TERF1-interacting nuclear factor 2 - TINF2). These genes encode proteins for maintenance of telomeres, which are located at the ends of chromosomes [5]. There are three modes of inheritance of DKC, including X-linked recessive, autosomal dominant and autosomal recessive.

TINF2- and TERC-related DKC are inherited in an autosomal dominant pattern. TINF2 is located on chromosome $14 \mathrm{q} 12$ and consists of 6 exons. The TIN2 protein is a component of the shelterin complex, which is involved in the protection of telomeres. Mutations in TINF2 have been reported in 11-20\% of all patients with DKC [6]. The patients present the classic clinical triad with severe aplastic anemia. TERC is located on chromosome 3q26 and comprises one exon with 451 base pairs. TERC is a component of the telomerase complex and functions in the extension of telomeres. Mutations in TERC have been reported in 6$10 \%$ of all DKC patients. Mutations of TERC are not only found in DKC, but also in other hematological disorders including aplastic anemia, myelodysplasia syndrome and nonhematological disorders such as pulmonary fibrosis and liver cirrhosis. Patients may present with aplastic anemia without typical mucocutaneous features [7].

This study examined mutations in TINF2 and TERC by direct DNA sequencing in a Thai patient with DKC who had the classic clinical triad and bone marrow failure. We identified a novel mutation in the TINF2 gene (c.845G $>$ T).

\section{Methods}

\section{Subject and DNA Extraction}

A blood sample was collected from a Thai patient with DKC at the Department of Medicine, Faculty of Medicine, Siriraj Hospital, Mahidol University, Thailand. The patient had the classic symptoms, including abnormal skin pigmentation, nail dystrophy and mucosal leukoplakia (fig. 1). The pedigree of the patient's family is shown in figure 2 . The clinical profile and laboratory data of this patient are provided in table 1. A total of 100 unrelated Thai employees were included as normal controls who had no clinical symptoms of DKC and no family history of DKC. Genomic DNA was extracted using the QIAamp ${ }^{\circledR}$ DNA Blood Mini Kit (Qiagen, Hilden, Germany) according to the manufacturer's instructions.

\section{Mutation Analysis}

Direct sequencing of all exons was used for mutation screening in TINF2 (NG_016650.1) and TERC (NG_016363.1). The primers were designed using the Primer3 software [http://bioinfo.ut.ee/primer3-0.4.0/ (June 13, 2014)] and are shown in table 2. The PCR mixture consisted of $125 \mathrm{ng}$ of DNA with $5 \mathrm{X}$ GoTaq ${ }^{\circledR}$ Flexi buffer $(5 \mu \mathrm{l}), 10 \mathrm{mM}$ dNTP $(0.5 \mu \mathrm{l})$, $25 \mathrm{mM} \mathrm{MgCl}_{2}(1.5 \mu \mathrm{l}), 10 \mu \mathrm{M}$ forward primer $(0.5 \mu \mathrm{l}), 10 \mu \mathrm{M}$ reverse primer $(0.5 \mu \mathrm{l})$ and $0.5 \mathrm{U}$ GoTaq ${ }^{\circledR}$ DNA polymerase (Promega, Madison, Wisc., USA). PCR was performed with a thermal cycler (Veriti ${ }^{\circledR}$; Applied Biosystems, Foster City, Calif., USA). PCR products were purified using ExoSAP-IT ${ }^{\circledR}$ (Affymetrix Inc., Santa Clara, Calif., USA) and sequenced using the BigDye ${ }^{\circledR}$ Terminator 3.1 Cycle Sequencing Kit (Applied Biosystems) and the ABI Prism Genetic Analyzer 3130 Automated DNA sequencer ${ }^{\circledR}$ (Applied Biosystems). 


\section{Denaturing High-Performance Liquid Chromatography}

The nucleotide changes in the DKC patient were compared with those in 100 healthy individuals using denaturing high-performance liquid chromatography (DHPLC) analysis. The PCR products were denatured at $95^{\circ} \mathrm{C}$ for $5 \mathrm{~min}$ and re-annealed by decreasing temperature until reaching $25^{\circ} \mathrm{C}$. The products $(5 \mu \mathrm{l})$ were injected into WAVE ${ }^{\circledR}$ cartridges of a DHPLC column (Transgenomic Inc., Omaha, Nebr., USA). The conditions of DHPLC for each PCR product were adjusted for optimal resolution.

\section{Results}

All exons in TINF2 and TERC were screened for mutations in a Thai female patient with DKC. A novel missense mutation (c.845G $>$ T) was identified in TINF2 (fig. 3). The mutation generates a codon change from arginine to leucine (Arg282Leu) in exon 6 of TINF2. This is a hot spot for mutation in DKC. The TIN2 protein consists of two domains, including a TPP1/TRF2-binding domain and a TRF1-binding domain. The hot spot for TINF2 mutations is found in a small region (amino acids 269-298) near the TRF1-binding domain. This missense mutation (c.845G $>$ T) was detected in the DKC patient but not in 200 alleles of healthy individuals. The DHPLC chromatogram was different between the patient and control group (fig. 4). The patient showed a heterozygous mutation in TINF2 consistent with the autosomal dominant inheritance mode of this gene. The pedigree of the patient is shown in figure 2 . The patient's father, sister and brother also suffered from DKC. Their symptoms are similar to those of the patient (fig. 1, table 1). The mutation in TINF2 in this patient resulted in a phenotype consistent with the classic clinical triad $[8,9]$. The clinical characteristics of the patient are also similar to the phenotype of TINF2 mutations from a previous study [8].

\section{Discussion}

In this study, we identified a novel mutation (c.845G>T) in TINF2. Approximately 11$20 \%$ of DKC patients have mutations in the TINF2 gene [6]. Missense mutations are the most common type of mutation in DKC. Most of the mutations are found in the DKC1 gene that is inherited in an X-linked recessive manner. The family history revealed that there was a male-to-male transmission (father-to-son), which firmly excluded X-linked recessive inheritance. Therefore, the mutation in this female Thai patient may be found in either autosomal dominant or autosomal recessive modes. Due to the pattern of inheritance in the patient's family members consistent with autosomal dominant fashion (fig. 2), the mutation in TINF2 is the most likely cause of disease. The identified mutation in this patient (c.845G>T) is located in exon 6, which is a frequently mutated region of TINF2.

We compared the sequence to other species such as rat, cattle, rhesus macaque and chimpanzee using MultAlin (http://multalin.toulouse.inra.fr) (August 4, 2014) and the alignment shows that the TINF2 gene is highly conserved in evolution (fig. 5). TINF2 encodes the TIN2 protein, which is a component of the shelterin complex. This protein is involved in protection of telomeres from DNA damage. This mutation (c.845G>T) occurs in amino acid residue 282, which is located in a region adjacent to the TRF1-binding domain of TIN2. This mutation changes an arginine to leucine (Arg282Leu), converting a positively charged group to a non-polar group, which may cause dysfunction of TIN2. A previous study reported that a mutation in TINF2 reduces the capability of TIN2 to associate with telomerase, leading to 
telomere shortening [10]. Thus, the novel mutation reported here may disrupt the telomereprotective function of TIN2, thereby resulting in shortened telomeres.

Other reports found that mutation at codon 845 (c.845G>A) results in an arginine change to histidine $[8,9]$. The patients in those studies were diagnosed with DKC, DKC/ Hoyeraal-Hreidarsson syndrome or DKC/Revesz syndrome. Clinical characteristics varied in terms of skin pigmentation, nail dystrophy, leukoplakia, aplastic anemia, epiphora, retinopathy and developmental delay. In addition, pulmonary fibrosis was found in another patient with TINF2 mutation in exon 6 [4]. However, the mechanism of pulmonary fibrosis in DKC is still unknown. Therefore, genotype-phenotype correlations between mutation in TINF2 and patient characteristics may be postulated. DKC is a rare disease and a case report was published on a Thai male patient with mutation in DKC1 (c.1058C >T) [11]. This is the first report of a female patient in Thailand with DKC. This study will help with molecular genetic diagnosis of DKC patients and family members. Furthermore, the data will be useful for genetic counseling and treatment of DKC patients.

\section{Acknowledgements}

This work was supported by the Siriraj Chalermprakiat Fund and a Mahidol University Grant (Talent Management Program) to B. Panichareon. T. Seedapan received a Siriraj Graduate Thesis Scholarship and Siriraj Research Fund, Faculty of Medicine Siriraj Hospital, Mahidol University.

\section{Statement of Ethics}

The patient gave written informed consent for this study. The study was approved by the Institutional Review Board (COA No. Si391/2014).

\section{Disclosure Statement}

The authors have no conflicts of interest to disclose.

\section{References}

1 Walne AJ, Marrone A, Dokal I: Dyskeratosis congenita: a disorder of defective telomere maintenance? Int J Hematol 2005;82:184-189.

2 Cole HN, Rauschkolb JE, Toomey J: Dyskeratosis congenita with pigmentation, dystrophia unguis and leukokeratosis oris. Arch Derm Syphilol 1930;21:71-95.

3 Dokal I: Dyskeratosis congenita. Hematology Am Soc Hematol Educ Program 2011;2011:480-486.

-4 Fukuhara A, Tanino Y, Ishii T, Inokoshi Y, Saito K, Fukuhara N, Sato S, Saito J, Ishida T, Yamaguchi H, Munakata M: Pulmonary fibrosis in dyskeratosis congenita with TINF2 gene mutation. Eur Respir J 2013;42:1757-1759.

5 Walne AJ, Dokal I: Advances in the understanding of dyskeratosis congenita. Br J Haematol 2009;145: 164-172.

6 Calado RT (ed): Progress in Molecular Biology and Translational Science, ed 1. Waltham, Academic Press, 2014.

7 Vulliamy T, Marrone A, Dokal I, Mason PJ: Association between aplastic anaemia and mutations in telomerase RNA. Lancet 2002;359:2168-2170.

8 Savage SA, Giri N, Baerlocher GM, Orr N, Lansdorp PM, Alter BP: TINF2, a component of the shelterin telomere protection complex, is mutated in dyskeratosis congenita. Am J Hum Genet 2008;82:501-509. 


\section{Case Reports in Dermatology}

\begin{tabular}{l|l}
\hline \multicolumn{2}{l|}{ Case Rep Dermatol 2015;7:212-219 } \\
\hline DOI: $10.1159 / 000439042$ & $\begin{array}{l}\text { C } 2015 \text { S. Karger AG, Basel } \\
\text { www.karger.com/cde }\end{array}$ \\
\hline
\end{tabular}

Panichareon et al.: Novel Mutation of the TINF2 Gene in a Patient with Dyskeratosis Congenita

-9 Walne AJ, Vulliamy T, Beswick R, Kirwan M, Dokal I: TINF2 mutations result in very short telomeres: analysis of a large cohort of patients with dyskeratosis congenita and related bone marrow failure syndromes. Blood 2008;112:3594-3600.

10 Mitchell JR, Wood E, Collins K: A telomerase component is defective in the human disease dyskeratosis congenita. Nature 1999;402:551-555.

-11 Viprakasit V, Tanphaichitr VS: Recurrent A353V mutation in a Thai family with X-linked dyskeratosis congenita. Haematologica 2001;86:871-872.

Table 1. Clinical profile and laboratory data

\begin{tabular}{ll}
\hline Clinical data and laboratory test & Result \\
\hline Diagnosis & DKC \\
Classic clinical triad & + \\
$\quad$ Nail dystrophy & + \\
$\quad$ Skin abnormality & - \\
$\quad$ Mucosal leukoplakia & + \\
Aplastic anemia & + \\
Pulmonary fibrosis & 4.4 \\
Hb, g/dl & 14.6 \\
Hct, $\%$ & 8 \\
Platelets, $\times 10^{3} / \mu \mathrm{l}$ & 5.74 \\
WBC, $\times 10^{9} / \mathrm{l}$ & \\
\hline
\end{tabular}

Table 2. Primers used for PCR amplification

\begin{tabular}{|c|c|c|c|}
\hline Fragment & Exon & Primer & $\begin{array}{l}\text { Product } \\
\text { size, bp }\end{array}$ \\
\hline \multicolumn{4}{|l|}{ TINF2 } \\
\hline 1 & 1 & $\begin{array}{l}\text { F: 5'-GTGGCCTTCTGACGCACCGT-3' } \\
\text { R: 5'-GCTCGCATCCCGCCCCTTTC-3' }\end{array}$ & 642 \\
\hline 2 & $2+3$ & $\begin{array}{l}\text { F: 5'-GCCCACAGCTTGGGGATGAG-3' } \\
\text { R: 5'-CTGGGCGACAGAGCAAGATT-3' }\end{array}$ & 484 \\
\hline 3 & $4+5$ & $\begin{array}{l}\text { F: 5'-GCCTGGCCACTAACCCAC-3' } \\
\text { R: } 5^{\prime} \text {-TCTTATGCCCGGAGCCCA-3' }\end{array}$ & 422 \\
\hline 4 & 6.1 & $\begin{array}{l}\text { F: 5'-CGGGCATAAGAAACCAGTTA-3' } \\
\text { R: 5'-TTCTCCTTCAGAGCCCTTCC-3' }\end{array}$ & 527 \\
\hline 5 & 6.2 & $\begin{array}{l}\text { F: 5'-GCCTGAGAGCAAGGAAGAAC-3' } \\
\text { R: 5'-TTCTGCTCCTTCCCACTCAC-3' }\end{array}$ & 553 \\
\hline 6 & 6.3 & $\begin{array}{l}\text { F: 5'-TGGTTTCCCTCCTACAGTGTG-3' } \\
\text { R: 5'-AGTTTGGAAGGGCCAGTTCT-3' }\end{array}$ & 652 \\
\hline \multicolumn{4}{|l|}{ TERC } \\
\hline 1 & 1 & $\begin{array}{l}\text { F: 5'-CCAGCCCGCCCGAGAGAGTG-3' } \\
\text { R: 5'-TGCAGCACACTGGCCCAGTC-3' }\end{array}$ & 672 \\
\hline
\end{tabular}


Case Reports in
Dermatology

Case Rep Dermatol 2015;7:212-219

DOI: $10.1159 / 000439042$

(C) 2015 S. Karger AG, Basel

www.karger.com/cde

Panichareon et al:: Novel Mutation of the TINF2 Gene in a Patient with Dyskeratosis Congenita

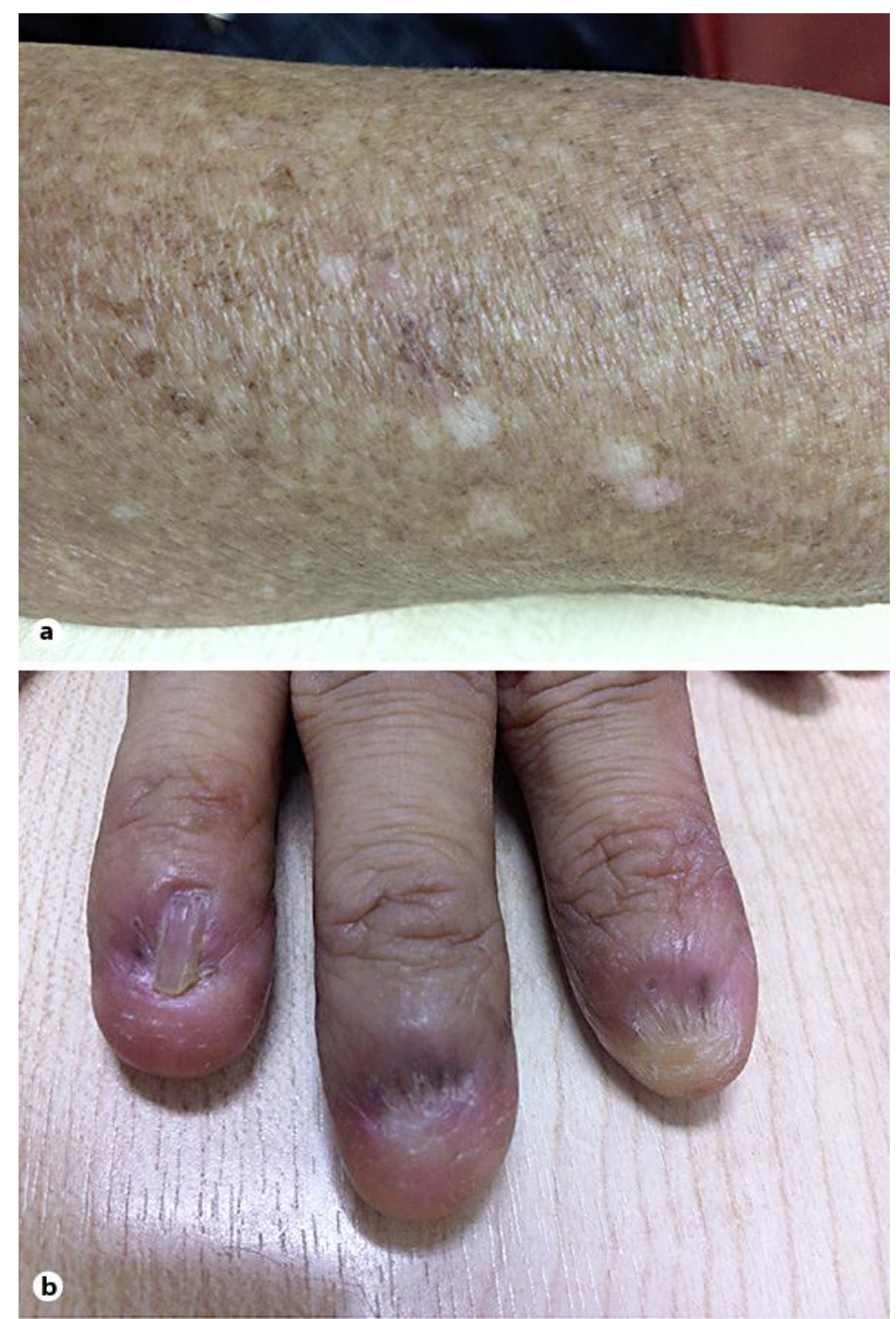

Fig. 1. A 37-year-old female who had skin pigmentation (a) and nail dystrophy (b). 
Panichareon et al.: Novel Mutation of the TINF2 Gene in a Patient with Dyskeratosis Congenita

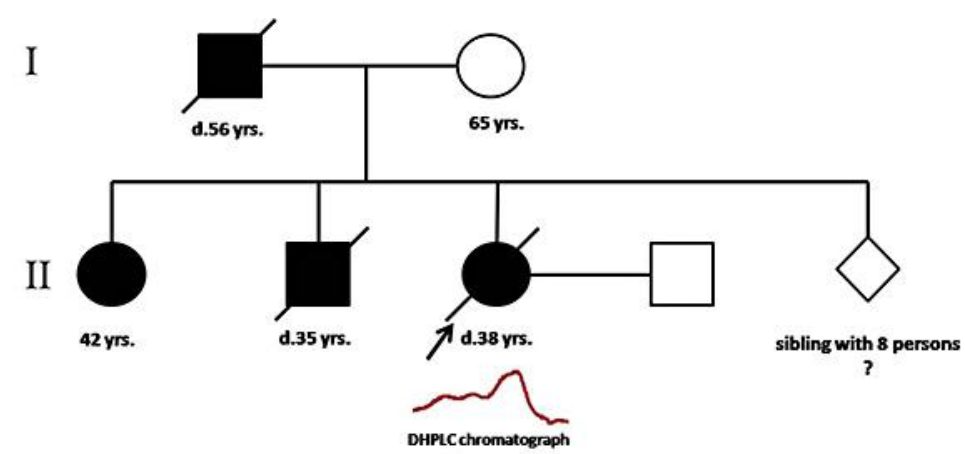

Fig. 2. The pedigree of a Thai patient with DKC. Her father, sister and brother also had clinical characteristics similar to that of the patient.

\section{A TA A G G $A$ C C C C C A A G T}

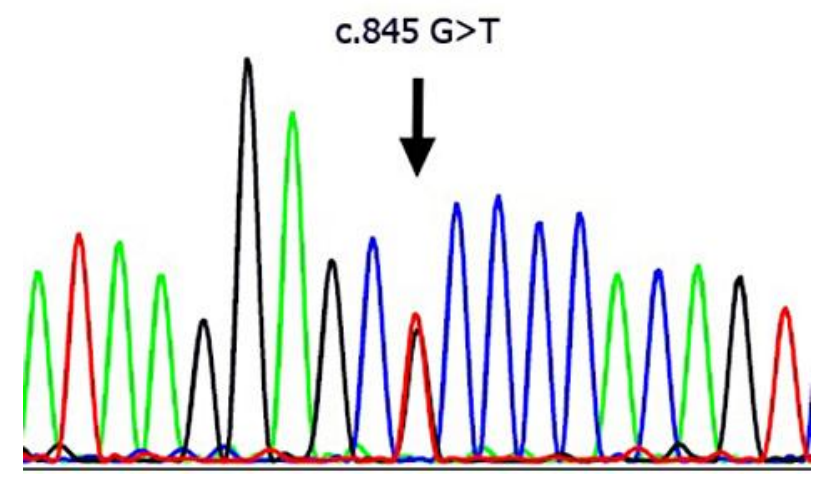

Fig. 3. Direct sequencing of TINF2 shows heterozygous c.845G>T in exon 6 . 
Panichareon et al.: Novel Mutation of the TINF2 Gene in a Patient with Dyskeratosis Congenita

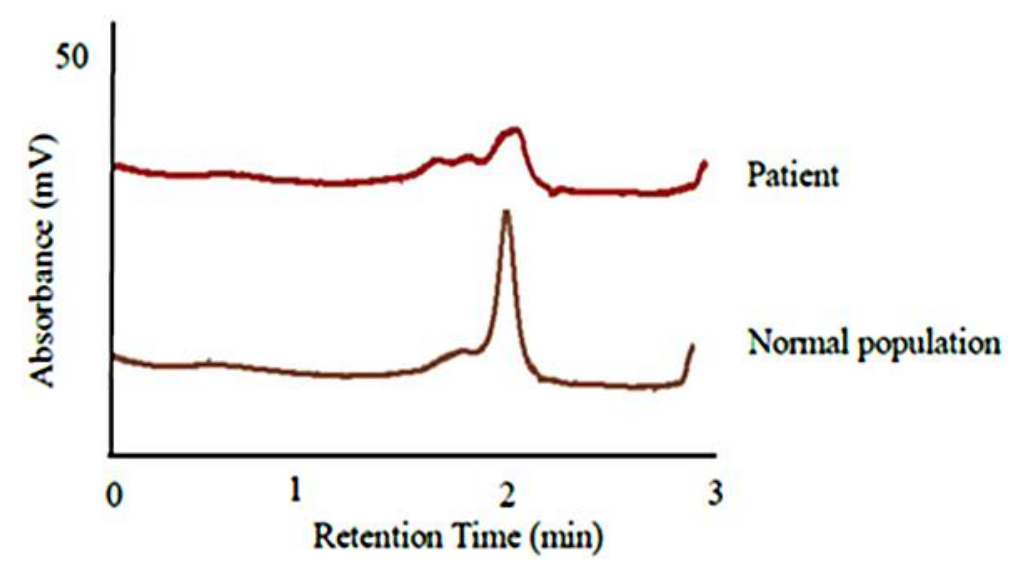

Fig. 4. The heteroduplex from DHPLC analysis of the DKC patient compared with the normal control population.

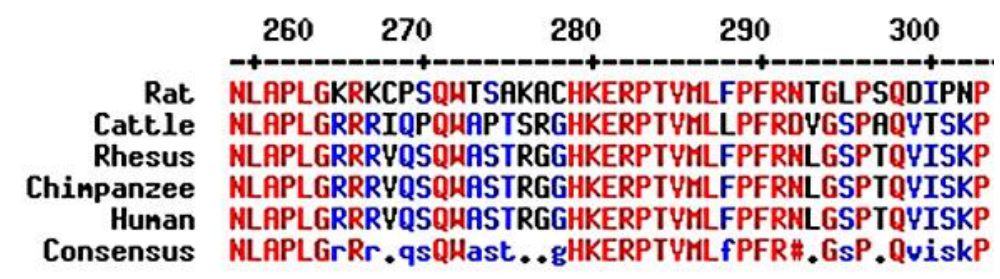

Fig. 5. Alignment of TIN2. The conserved residues are shown in red and low consensus residues are shown in blue. 